\title{
Effects of $\beta$-Lapachone at Non-Toxic and Toxic Concentrations on the mRNA Levels of XRCC1, GADD45A and LIG4 Genes
}

\author{
Fatemeh SANIE-JAHROMI, Hamideh MAHMOUDINASAB, *Mostafa SAADAT \\ Department of Biology, College of Sciences, Shiraz, University, Shiraz, Iran \\ *Corresponding Author: Email: saadat@shirazu.ac.ir
}

(Received 10 Feb 2018; accepted 24 Feb 2018)

\section{Dear Editor-in-Chief}

Most of anti-cancer drugs have mutagenic, clastogenic, and carcinogenic properties. Studies on oncology nurses and personnel handling cytostatic drugs showed that the frequencies of chromosomal aberrations, sister chromatid exchanges, and micronuclei were significantly increased in personnel handling anti-cancer drugs compared to control group (1). $\beta$-Lapachone ( $\beta$-Lap) is an anti-cancer drug which exerts cytotoxic effect via its induction of ROS generation which ultimately leads to DNA damage (2). Nucleotide excision repair (NER), base excision repair (BER), and non-homologous end joining repair (NHEJ) pathways are very important in genome stability. XRCC1 (OMIM: 194360, an essential scaffolding protein for both long and short patch BER), GADD45A (OMIM: 126335, a growth arrest and DNA-damage-inducible protein) and LIG4 (OMIM: 601837) have important roles in the BER, NER, and NHEJ pathways, respectively. LIG4 efficiently joined single-strand breaks in a double-stranded polydeoxynucleotide in an ATPdependent reaction (3). LIG4 efficiently joined single-strand breaks in a double-stranded polydeoxynucleotide in an ATP-dependent reaction. LIG4 efficiently joined single-strand breaks in a double-stranded polydeoxynucleotide in an ATPdependent reaction. Depletion of XRCC1 dramatically sensitized cells to $\beta$-Lap (4) and Gadd45a-null mice showed genomic instability (5). $\beta$-Lap efficiency can be affected by NHEJ performance (2). Due to anti-cancer property of $\beta$-Lap, so it's occupationally exposure as a public health concern is expected.

To our knowledge there is no study on the effect of $\beta$-Lap on the transcript levels of XRCC1, $G A D D 45 A$ and LIG4 genes. Therefore the present study was carried out.

SH-SY5Y neuroblastoma cell was cultured in DMEM/F12 enriched with 10\% FBS (Gibco), penicillin (100 U/ml, Sigma) and streptomycin $(100 \mu \mathrm{g} / \mathrm{ml}$, Sigma). The cells were seeded at $3 \times$ $10^{5}$ cells $/ \mathrm{ml}$ and incubated at $37^{\circ} \mathrm{C}$ for $24 \mathrm{~h}$ and then cells were treated with $\beta$-Lap. Cells were harvested after $24 \mathrm{~h}$ and RNA extraction was done. Quantitative real-time PCR and primers specific for the examined genes were described previously (6). 3.2 and $2.0 \mu \mathrm{m}$ M $\beta$-Lap showed about $18 \%$ cytotoxicity and no cytotoxicity, respectively. The experiments were done in triplicates. Data were shown as means \pm standard error (SE).

Figure 1 shows the alteration of mRNA levels of XRCC1, GADD45A and LIG4 genes in different treatments. The XRCC1 mRNA level was significantly decreased at non-toxic concentration. The $G A D D 45 A$ mRNA levels did not alter at nontoxic concentration of $\beta$-Lap, however, it was significantly increased at toxic concentration of $\beta$-Lap, compared with the control culture. The mRNA levels of LIG4 were significantly decreased at both toxic and non-toxic concentra- 
tions of $\beta$-Lap. The expression levels of the XRCC1 and LIG4 significantly decreased at nontoxic concentrations of $\beta$-Lap, cellular DNA repair system cannot repair DNA damages.
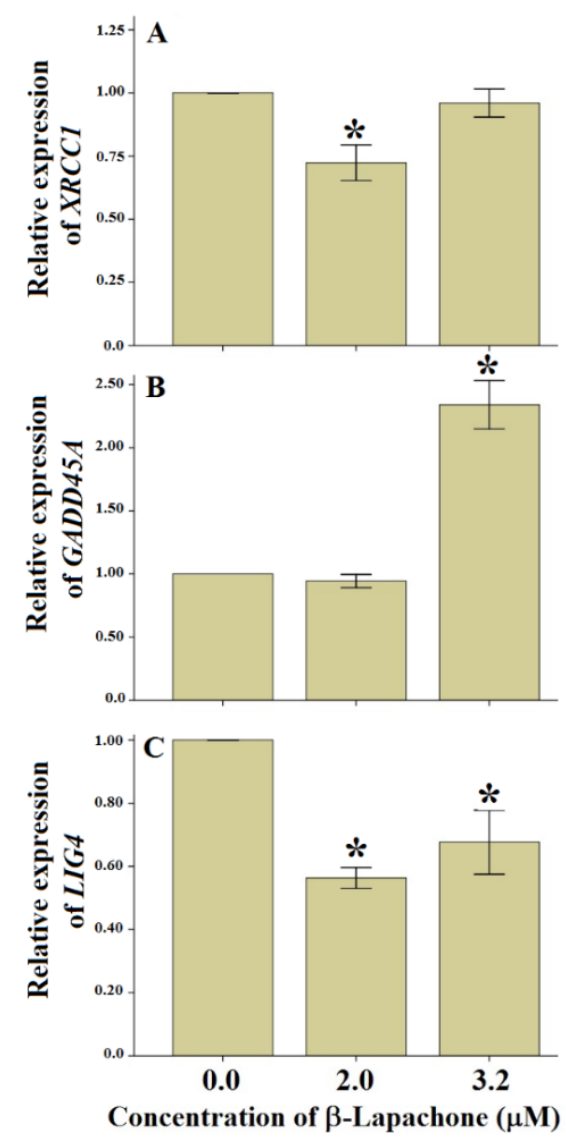

Fig. 1: mRNA levels of the XRCC1 (A), GADD45A (B) and LIG4 (C) genes at two concentrations of $\beta$ Lapachone; 2.0 (non-toxic) and $3.2 \mu \mathrm{M}$ (toxic) concentrations. $\mathrm{n}=3$, mean $\pm \mathrm{SE}$. $* \mathrm{P}<0.05$ all values compared with control cultures using Duncan post hoc test

We know that nurses of oncology departments and workers handling neoplastic drugs showed higher chromosomal damage compared to control persons (1), which may interpreted by their lower DNA repair capacity due to exposure of non-toxic levels of anti-cancer drugs. Alterations in mRNA levels of DNA repair related genes seem to be a rapid, simple and sensitive method for biomonitoring of effect(s) of occupationally exposure to anti-cancer drugs.
For public health programs, the early detection of alterations may permit the adoption of preventive biological controls such as hygienic improvements in the workplace or the reduction of work hours. Further experiments needs to investigate the effects of other anti-cancer drugs of expression levels of DNA repair genes at non-toxic concentrations.

\section{Acknowledgements}

This work was supported by the Shiraz University, Iran (Grant number: 93GCU1M1741).

\section{Conflict of interest}

The authors declare that there is no conflict of interests.

\section{References}

1. Ladeira C, Viegas S, Pádua M et al (2014). Assessment of genotoxic effects in nurses handling cytostatic drugs. J Toxicol Environ Health A, 77(14-16):879-87.

2. Bentle MS, Reinicke KE, Dong Y et al (2007). Non-homologous end joining is essential for cellular resistance to the novel antitumor agent, beta-lapachone. Cancer Res, 67(14):6936-45.

3. Robins P, Lindahl T (1996). DNA ligase IV from HeLa cell nuclei. $J$ Biol Chem, 271(39):24257-61.

4. Chakrabarti G, Silvers MA, Ilcheva $M$ et al (2015). Tumor-selective use of DNA base excision repair inhibition in pancreatic cancer using the NQO1 bioactivatable drug, $\beta$ lapachone. Sci Rep, 5:17066.

5. Hollander MC, Sheikh MS, Bulavin DV et al (1999). Genomic instability in Gadd45adeficient mice. Nat Genet, 23(2):176-84.

6. Sanie-Jahromi F, Saadat I, Saadat M (2016). Effects of extremely low frequency electromagnetic field and cisplatin on mRNA levels of some DNA repair genes. Life Sci, 166: 41-5. 